\title{
Imagen de China y su representación en la prensa española en las décadas de 1960 y 1970: el caso del ABC
}

\section{China's image and representation in the Spanish press in the 1960s and 1970s: the case of ABC}

\author{
AUTOR \\ Sergio Sánchez Fraile \\ https://es.linkedin.com/in/sergio-sánchez-fraile-72779646
}

\section{RESUMEN}

A lo largo del siglo XX la prensa escrita se conforma como uno de los generadores de opinión más importantes. Al margen de su papel como fuente primaria puede servir para valorar como se percibe China, en el sentido más amplio del término, $\mathrm{y}$ "lo chino". El autor trata de indagar en los diferentes matices representados en la prensa que construyen la percepción de China en el imaginario de la sociedad española durante la década de 1960 y 1970. Para el estudio, se han analizado aquellas referencias que contenían la palabra "China" en publicaciones durante ese periodo en el diario $A B C$, el segundo periódico de mayor tirada en España, y el primero en Madrid. Se trata de examinar cómo la prensa influye en la construcción de una China imaginaria que arrastra los tópicos tradicionales (misteriosa, cerrada, mística) y le añade unos nuevos, propios del contexto de Guerra Fría. Además se examina de qué manera China se construye como una amenaza multilateral para occidente (racial, social, político, religio-

\section{ABSTRACT}

Over the 20th century print media appears as one of the most important opinion-generating agent. Besides its role as primary source, it can be used to value how China, in the broadest sense, and "the chineseness" are perceived. The author tries to inquire about the different represented nuances on the press that build the perception of China in the imaginary of the Spanish society during 60's and 70's. For this study, references in $A B C$ newspaper which contain the word "China" from these years have been analyzed. $A B C$ was the widest print circulation newspaper in Madrid and the second one in Spain. The aim is to examinate how the press have influenced the construction of an imaginary of China, which carries the traditional clichés (mysterious, hermetic, mystic) and adds some news more suited for Cold War context. Finally, the author reviews the modelling of China as a multilateral menace for western countries (racial, social, political, religious and military menace); and how this menace fits not only 
so y militar); y como esta amenaza encaja no solo dentro de la paranoia anticomunista sino del debate poscolonial de la segunda mitad del siglo XX.

Palabras clave: China; España; imagen; percepciones; prensa; siglo XX in the anti-communist paranoia but also in the second half 20th century's post-colonial discourse.

Keywords: 20th century; China; image; perceptions; press; Spain

\section{INTRODUCCIÓN}

Las décadas de 1960 y 1970 se encuentran irremediablemente marcadas por las dinámicas de Guerra Fría. Durante estos veinte años tendrán lugar los acontecimientos de mayor tensión política y militar (sobre todo durante la década de los sesenta) así como el inicio de la distensión (durante la década de 1970) que tendrá su declive definitivo en los años 80 (Duara, 2011). En esta situación China juega un papel determinante en la despolarización de los actores implicados en la Guerra Fría y más aun a partir de la ruptura de las relaciones con la Unión Soviética a mediados de los años 60 (Dittmer, 2011; Lia, 2011). La implantación y el estrepitoso fracaso a finales de los 50 del Gran Salto Adelante (大跃进 Dàyuèjin), política económica que tenía como objetivo la rápida industrialización y colectivización de la República Popular China deja a Mao Zedong (毛泽东 Máo Zédōng) pendiente de un hilo y los sectores más conservadores del Partido Comunista Chino (PCCh) tratan de mermar su poder político. Ante la perspectiva de ser objeto de una "desestalinización" como la que había llevado a cabo Kruschev en Rusia tras la muerte de Stalin, Mao trata de reforzar su imagen y recuperar el poder político a través de lo que se ha conocido como la Gran Revolución Cultural Proletaria (无产阶级文化 大革命, wúchăn jiējí wénhuà dàgémìng, o simplemente 文化大革命, wénhuà dàgémìng) o Revolución Cultural. El proceso se lleva a cabo a través de la persecución política e ideológica de ciertos sectores del PCCh que suponían una amenaza para la continuación de la Revolución China. Al mismo tiempo, Mao se fortalece como líder político y evita la pérdida de poder (MacFarquhar y Schoenhals, 2009; Spence, 2011).

Para gran parte de los sectores de izquierda en los países occidentales, la Revolución Cultural china suponía una renovación del espíritu revolucionario que se había quedado estancado en la Unión Soviética, más preocupada por la burocratización del estado (Kessel, 1972 y 1978; Fields, 1984; Elbaum, 1998; Río, 2005; Cardina, 2010; Buchanan, 2012;). Pero no solo eso. Como se ha dicho la entrada de China en el juego internacional genera un nuevo actor de extrema importancia que ha de ser comprendido tanto por los propios estados como por sus sociedades.

En el proceso de elaboración de una imagen de China en la sociedad española juega un papel decisivo la entrada en la ONU y el posterior establecimiento de las relaciones con EEUU y otros países dentro de su órbita de influencia, entre ellos España. El fin de la política de Yalta se hacía efectivo, y el acercamiento entre China y EEUU, más marcado a partir de la visita de Nixon en 1972, cataliza los mecanismos diplomáticos. España acabará estableciendo relaciones diplomáticas con la República Popular China en 1973 hecho que no pasa desapercibido ni a la prensa ni a los lectores. Esta normalización de las relaciones pasa por una relajación informativa y como veremos más adelante hay un cambio en la manera de ver al país asiático. 
Desde el punto de vista de la historia de España, este periodo coincide con los intentos de apertura y el desarrollismo del Franquismo español (lo que se conoce como el Segundo Franquismo), así como con su etapa final y parte de la transición democrática (Moradiellos, 2000). Dentro de estos conatos de apertura en 1966 encontramos la nueva "Ley de Prensa" elaborada por el Ministro de Información y Turismo D. Manuel Fraga Iribarne. Aún con todas las restricciones y lejos de suponer una libertad de prensa completa (Gómez-Reino y Carnota, 2007; Chuliá, 1999; Davara, 2005) sobre todo a consecuencia del Articulo Segundo, que limitaba la libertad de expresión, suponía un importante avance en la empresa periodística, dando un papel más determinante a la iniciativa privada por encima de la propaganda de la prensa estatal. (Ley 14/1966, p.3310)

Este trabajo se centrará principalmente en la labor del diario ABC y su suplemento "Blanco y Negro", que durante este periodo es el segundo periódico de mayor tirada en España, y el primero en Madrid. Fundado el 1 de Enero de 1903 por Torcuato Luca de Tena y Álvarez Ossorio, es uno de los periódicos más antiguos que hoy en día continúan publicándose junto con "La Vanguardia", fundada en 1881. Abiertamente conservador, católico y monárquico(1) (Olmos, 2002) fue uno de los periódicos principales durante los cuarenta años de Franquismo en España apoyando el régimen aunque con algunas reservas.

En el periodo que nos corresponde es nombrado director por segunda vez en 1962 Torcuato Luca de Tena, nieto del fundador. Aun coincidiendo con este periodo de apertura, el periódico va progresivamente girando hacia la derecha, demasiado incluso para las posiciones del régimen franquista (Olmos, 2002, p.429). Bajo su dirección defiende la postura gubernamental respecto al "Proceso de Burgos" e insta al gobierno a ejecutar a los miembros de ETA, aunque finalmente se retracta. Además apoya sin reticencias el golpe de Pinochet en Chile contra el gobierno legítimo de Salvador Allende (Olmos, 2002, p.433-442). En 1975 Torcuato Luca de Tena es sustituido tras la muerte de su padre y protector por José Luis Cebrián. Existía en ese cambio la intención de moderar el discurso derechista y ultraconservador que el diario había tomado, sin embargo no se consigue por la influencia que Luca de Tena aún mantiene. Por lo cual, tras la muerte de Franco el periódico $A B C$ se convierte en una auténtica trinchera del tardofranquismo, lo que supondrá un notable descenso de lectores y ventas (Olmos, 2002, p.520-525). Ya en 1977 se produce el cambio significativo que permitirá la entrada del $A B C$ en el mundo de la transición democrática, a partir de la dirección de Guillermo Luca de Tena, que permanecerá como director hasta 1983. El comienzo de esta etapa, que se caracteriza por una apertura liberal bajo la influencia del periodista Pedro J. Ramírez, fue difícil de entender por parte del equipo de dirección y los lectores.

Todos estos factores influirán en la manera de ver, comprender y representar China en la sociedad española, que si bien no se encontraba para muchos en el punto de mira del interés informativo se va poco a poco haciendo hueco en el imaginario y en la opinión pública general.

\section{METODOLOGÍA}

Como se ha dicho anteriormente, el trabajo se centra principalmente en la representación que el diario ABC y su suplemento "Blanco y Negro", hacen de la imagen de China. Esta proyección genera una percepción en el imaginario de la sociedad española que se acomodará más o menos a una serie de preconcepciones que se asumen sobre China. La elección del periódico 
se debe principalmente al impacto de este durante los años sesenta y setenta (Olmos, 2002, p.457)(2), así como la disponibilidad de sus documentos a partir de la hemeroteca digital del diario. Aun así es preciso señalar que el proceso de recopilación de documentos en este portal digital es en algunos casos innecesariamente engorroso y sería recomendable una revisión del sistema.

Para el análisis se ha realizado un vaciado de fuentes documentales extraídas de la hemeroteca digital con una búsqueda avanzada bajo el término "China" entre el 1 de Enero de 1960 hasta el 31 de Diciembre de 1979, obteniendo un resultado de 29.497 referencias(3) Tras esto se realizó un cribado de entradas que carecían de interés para la investigación: publicidad repetida, referencias aisladas, errores de búsqueda, otras entradas duplicadas, etc., y se seleccionaron las noticias relevantes. Este cribado permitió generar veinte documentos digitales (PDF) clasificados anualmente y preparados para el análisis, que constituían un total de 5103 páginas (2936 para la década de 1960 y 2167 para 1970) del diario ABC y su suplemento "Blanco y Negro". A partir de ahí se clasifican las entradas a partir de su temática y su correlación cronológica: sobre la Revolución Cultural, la admisión de China en la ONU, la ruptura sino-soviética, catolicismo en China, relaciones entre China y España, etc., para poder después realizar el análisis que se mostrará en las siguientes páginas.

Este estudio es esencialmente cualitativo, y aunque también se realiza un breve análisis cuantitativo. Si nos distanciamos para observar los números la cantidad de referencias sobre "China" puede darnos una idea aproximada de la progresiva atención que China recibió durante estos veinte años, pero si no se examinan con relativo cuidado los números pueden llevarnos a un error interpretativo.

Así mismo son necesarias algunas aclaraciones metodológicas. En la mayor parte de las citas mostradas en este trabajo no se hace diferenciación entre artículos publicados en la edición diaria del periódico (ya sea en la edición madrileña o la sevillana) o bien en el suplemento "Blanco y Negro". Esto se debe a que en el proceso de clasificación de los documentos no se hizo una distinción especial. Aunque la maquetación y la edición son diferentes, los autores y las ideas son prácticamente idénticos, y podemos considerar una monografía publicada en "Blanco y Negro" como un documento propio del diario ABC.

Es importante remarcar que este trabajo no trata de desmentir o confirmar si los hechos que cita el $A B C$ son verdaderos o no, sino como los transmite, con qué intención los muestra, y cuál es el efecto que tienen estas noticias en los lectores españoles a la hora de generar su propia opinión sobre China.

\section{RESULTADOS}

El objetivo principal de este trabajo es la interpretación de la imagen que el $A B C$ provee de China a sus lectores y qué supone esto para la sociedad española. Así entender la forma en la que la prensa trabaja sobre China dentro del ámbito meramente periodístico ayuda a poner el objetivo en contexto. Según informa (ABC, 8 Mayo 1973, p.31) en una nota de prensa tras el inicio de los contactos diplomáticos España-China, comenzará a prepararse el primer grupo de periodistas españoles que trabajaran desde Beijing. 
La sensación general es que existe un reconocido desconocimiento sobre China, y en muchas ocasiones se disculpan por la precaria situación informativa, aunque se justifica siempre por la situación política china que impide un seguimiento directo de los acontecimientos. Sin embargo, sí hay una intención real por conocer la RPC y transmitirlo, al lector. El desconocimiento no se traduce en falta de interés, ni por parte del periódico ni de los lectores, como muestra la gran cantidad de libros editados sobre China en este periodo así como el número de referencias que aparecen sobre China.

Existen en las publicaciones realizadas entre 1960 y 1979 principalmente dos picos en los que las referencias destacan: a) Entre 1965 y 1967, y b) entre 1971 y 1973. En el primer caso, comienza con la cobertura de los medios de la posible entrada de China en la Guerra de Vietnam y su desarrollo de armamento atómico; y continua con los dos años más convulsos de la Revolución Cultural. El segundo pico corresponde sobre todo con el proceso de apertura de la República Popular China y su entrada en la ONU, lo cual incluye la visita de Nixon y de los Reyes de España. De esta manera se pueden descartar con cautela algunas hipótesis.

No se observa ningún vínculo estrecho entre los acontecimientos de Mayo de 1968 en París y la RPC. Se podría pensar que la entrada del maoísmo en España se produce a través Francia y del movimiento de Mayo del 68. Desde luego estos datos no desechan esta hipótesis, pero no parece a partir de los datos del $A B C$ que la prensa sostuviera ese vínculo al menos de forma directa. A nivel informativo, la Revolución Cultural termina en 1967, aunque al menos hasta 1969 tenga fuertes consecuencias en China, lo cual podría llevarnos a error si solo nos quedamos con los datos cuantitativos.

Estos dos picos informativos marcan las dos posturas que la prensa refleja sobre China y que se analizan más adelante: China como amenaza multilateral, durante los años sesenta, y China como país en proceso de apertura internacional. En el primer caso se aprecia como el interés va in crescendo según avanza la tensión política y militar en el contexto de la Guerra Fría desde 1962 en su punto más bajo, hasta 1966, punto más alto que se corresponde con el comienzo de la Revolución Cultural. En el segundo caso, comienza en 1971 con la preparación y entrada de China en la ONU, sigue con el viaje de Nixon y finaliza con el reconcomiendo de la RPC por el gobierno español en 1973, para mantenerse en números más bajos hasta 1979, con la normalización de las relaciones y los gobiernos de Hua Guofeng y Deng Xiaoping.

Otro análisis que podemos hacer de los datos es que no existe un aumento progresivo de la atención que se le da a China sino que prácticamente se mantiene estable en ambas décadas. De hecho es ligeramente superior en la década de 1960, lo que nos indica que en realidad la paulatina apertura de China no supone un aumento significativo de interés por parte de la prensa y/o de los lectores. Incluso si rompemos la barrera y nos vamos a la década de los años ochenta los datos se mantienen similares y no modifican apenas el promedio total(4). 


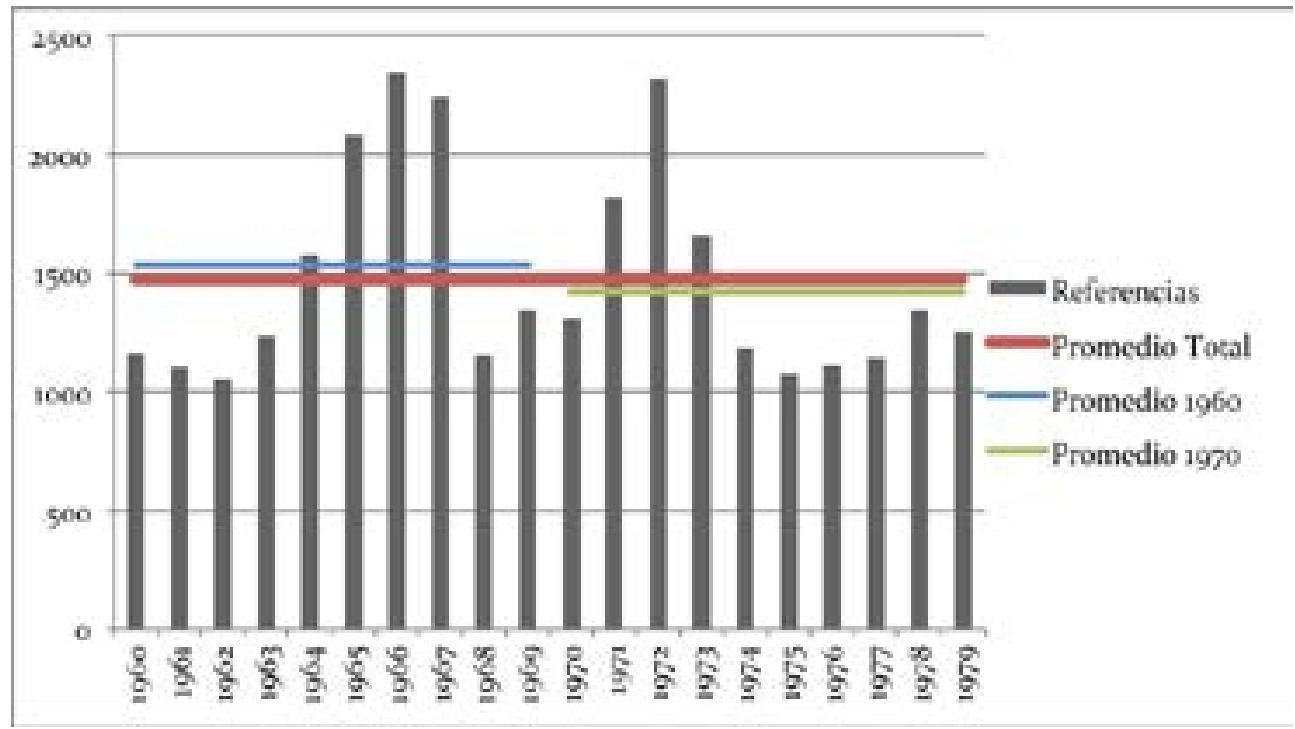

Paralelamente, se ha de analizar también el formato en el que gran parte de estas referencias venían incluidas y quiénes escriben sobre China. Aunque no son verdaderos expertos hay varios periodistas que siguen de cerca toda las noticias e informaciones que provienen de la prensa extranjera sobre China durante este periodo y que conforman algunas de las grandes figuras tanto del periódico $A B C$ como de la historia del periodismo español, llegando a ocupar puestos clave dentro del diario: Luis María Anson (director del ABC, 1983-1997), Vicente Gállego, Manuel Aznar (antiguo director de La Vanguardia), Andrés Travesí (redactor jefe del ABC), Raymond Cartier, Roberto de Arenzaga, Baltasar Porcel....

Por otro lado, las noticias relacionadas con China aparecen en varios formatos, entre ellos: Monográficos, notas de prensa, editoriales y columnas de opinión.

A pesar de que el estudio original contenía un breve análisis sobre la representación de la historia reciente de China en el diario este ha sido descartado para dar más importancia a algunas discusiones menos históricas.

\section{Nombres}

En la historiografía de China han corrido ríos de tinta sobre el origen y las implicaciones del nombre "China" a lo largo de toda su historia. En este caso no se entrará en debates sobre si es un nombre propio o impuesto sino simplemente en el alcance que este tiene durante los dos decenios que se han propuesto analizar. Lo que parece claro, como afirma Arif Dirlik (2015) es que el término "China" parece comprender una región (geográfico), el estado que gobierna esa región (político), y la civilización que la ocupa (social y cultural), y que juntando todo en un simple concepto se abole toda la complejidad espacial, temporal y social de este área. De este modo, "chino" sugiere una homogeneidad cultural entre sus habitantes, sus prácticas políticas y sociales, así como su lengua, su cultura y su religión. Pero, ¿qué significa para la prensa española, más concretamente para el $A B C$ ? Si bien en un primer vistazo podría parecer que no supone ningún problema, el asunto cambia en el momento en el que analizamos las fuentes. 
¿Qué era China durante las décadas de 1960 y 1970?

Con el éxito de la revolución china en 1949 y el éxodo del Kuomintang a la isla de Taiwán (Formosa) se crea una ambigüedad de conceptos. El reconocimiento de la República Popular China por parte de la comunidad internacional tardaría en llegar, y sólo algunos países del ámbito comunista declararon su apoyo a la recién creada república popular.

Durante los años sesenta para el ABC "China" era lo que conocemos como Taiwán, y los apelativos más comunes eran "China Nacionalista" o "Formosa". Sin embargo el término no era de uso exclusivo para Taiwán. Para la RPC generalmente se recurrían a adjetivos propios de países comunistas: la "China Roja", "China Comunista" o "Pekín" para acabar de desvincularla con el concepto tradicional de "China". De hecho, en muchas ocasiones se continua usando "Peiping", antiguo nombre de Beijing durante la Republica, momento en el que Nanjing era la capital.

Sin embargo, durante este periodo se ven titulares en los que, si no se profundiza en la lectura de la noticia, hoy no sabríamos de que se está hablando, mientras que en la época se daba por sentado que se trataba de la China Nacionalista en la isla de Formosa.

A finales de los sesenta y ya en los setenta se va produciendo un cambio progresivo en el que China pasa a ser la Republica Popular China aunque no sin otros apelativos, mientras que la "China Nacionalista" pasa a ser Taiwán o Formosa.

Huelga decir que no se trata únicamente de una cuestión nominativa sino de una representación de la política internacional de la RPC y de Taiwán en el contexto de la Guerra Fría. Más aun en el caso de España, donde las buenas relaciones establecidas con Taiwán dificultan la entrada de una terminología más neutral y donde sólo después del pleno reconocimiento de la RPC se relaja el discurso anticomunista, y los términos usados al hablar de los intercambios comerciales con China también se neutralizan (China Continental)

\section{Construcciones}

China se representa en el diario $A B C$ como dos entes que son en realidad uno solo. Ya no por la existencia más o menos real de "dos chinas", sino por la dicotomía que se crea entre una China que es real, $y$ otra que quiere ser real en el imaginario de los redactores y lectores del $A B C$. Esta dicotomía es anacrónica, ya que este ideal está vinculado a una China tradicional, que si bien no ha sido destruida por completo, no existe ya en la manera en la que se representa en la prensa y en la que la perciben sus lectores. Existe una tendencia general a la idealización de la China tradicional, idealización que a su vez está orientalizada (y "auto-orientalizada" en palabras de A. Dirlik (1996)) y que se sostienen la una a la otra de forma recíproca.

Los temas típicos que conforman este imaginario dibujan una China misteriosa y críptica, un modelo real que nos muestra cuan insólito puede ser el mundo en el que vivimos y las costumbres exóticas que tienen otros seres humanos. Incluso no se pone en duda cuando el diario habla de canibalismo durante las hambrunas del Gran Salto Adelante. Mucho se ha hablado de estas prácticas durante la segunda mitad del siglo XX en China, sin embargo las fuentes no pueden confirmarnos esas "olas de canibalismo" que sugiere el ABC.

De esta forma tiene lugar una desposesión identitaria. Es decir, la China que existe, la República Popular China, es arrebatada de sí misma para ser conservada en otra parte, lejos de su pro- 
pia entidad, mantenida en un stand by cultural y atemporal, a la espera de ser retomada más adelante, intacta y auténtica. China no puede ser en sí misma mientras siga siendo comunista. Sin embargo, China es China en sí misma y no viene definida por el imaginario de lo que "ha de ser China" de "lo chino", ni necesita la aprobación de agentes externos para ser confirmada en su realidad. La pérdida de cultura material o inmaterial supone un desastre pero no define lo que ha de ser un país, y mucho menos si esto viene alimentado por un imaginario externo, orientalista y en muchos casos poscolonial, como es el occidental durante la segunda mitad del siglo XX.

En esta construcción, China es todo aquello que nos permite diferenciarla de occidente. Las semejanzas con los países occidentales la alejan de sí misma, de su esencia vital. Es el tradicional antagonismo del "yo" frente al otro, en el que Europa se define como una "no-China". Así, China ha de definirse como un empaque de adjetivos cuantitativos y cualitativos que le permitan mantener su lugar en la historia.

La revolución (y lo revolucionario) por ir en sentido contrario de lo tradicional es en sí misma "no-china", y no encaja de ninguna manera en el imaginario occidental de Oriente: La revolución es, en cuanto al lenguaje, occidentalista y simplificadora. [...] La revolución china, que aspira a ser la más avanzada busca sus modos de expresión literaria en el Occidente y en el pueblo. [...] Un nacionalista [chino] es un hombre que escribe difícil y pinta complicado. Un marxista es un hombre que escribe como habla y se ahorra los cursos de pintura de diez o doce años. Pintura de Confucio. Vocabulario de Confucio. En fin: el gran secreto y el orgullo de los viejos chinos anteriores a la revolución." (ABC, 21 Enero 1972, p.27)

La negación de la "orientalidad" de China convierte automáticamente al país asiático en "occidental", que se autodefine como inherentemente simple y pragmático.

"China" es la China vista por Marco Polo. La del papel, la escritura y la pólvora. La del esencialismo frente al materialismo, del idealismo frente al pragmatismo, y del inmovilismo frente al dinamismo cultural de Occidente. Todos ellas dicotomías imaginadas en una construcción orientalista del mundo por parte del eurocentrismo.

Se afirma en algunos casos, que la cultura y civilización China (oriental) no son inmóviles, dando la razón a Arnold Toynbee (1977) pero con muchas reservas. Afirman que aunque no sea una inmovilidad absoluta, si lo es respecto a la cultura occidental que se ha desplazado a una velocidad infinitamente veloz, y que este estatismo queda evidenciado por el inmovilismo político (dictadura), artístico (métodos pictóricos y arquitectónicos idénticos), social (castas), y cultural (condicionado por el anquilosamiento político y social) con un resultado que se traduce en un atraso generalizado, no solo en China sino en todas las civilizaciones asiáticas. Es el hombre occidental de la acción y la práctica, contra el oriental de la contemplación y la especulación. Todo esto argumentado sobre la base religiosa de ambas "civilizaciones" (ABC, 11 Mayo 1963).

Esta China imaginada se puede encontrar en parte en Taiwán, donde aún se conservan tradiciones más antiguas y donde el comunismo aún no ha llegado.

"Realmente, si se quiere conocer la auténtica vida tradicional de los chinos hay que visitar Formosa. Ni en Hong-Kong o Macao, encrucijadas de culturas y tensiones, ni en 
el continente gobernado hoy por esos comunistas de los que Jivago decía que "no son hombres, son piedras", se encuentra el viajero con la faz íntima del alma china, como en Hualien, como en Taichun, como en Kachsiung, donde viven los chinos reales [...]. Taiwán es la China de la nostalgia, del exilio y la esperanza." (ABC, 31 Mayo 1967)

El chino es un pueblo que conserva "la profunda vejez de la sabiduría" pero no este pueblo chino, sino otro que era, otro pueblo que existe bajo el sustrato de la RPC, que existe pero no aquí sino en otra realidad. En ocasiones se representa a China aludiendo a una voluntad popular, a una exigencia infantil sobre la China que está en nuestra mente, la que nos ha arrebatado el comunismo, la China autentica que volverá, ya que en realidad sigue existiendo, porque es la única que conocemos.

\section{Preconcepciones}

En todo este proceso de construcción mental las preconcepciones orientalistas tienen la labor de cimentar el resultado final. China siempre se describe como inmensa, oscura, misteriosa, indescifrable, incógnita, lejana, cerrada... Un mundo por descubrir. No hay en China espacio para la claridad, la simpleza y la sencillez. Si bien esto cambia a partir de la segunda mitad de los años setenta es un cambio que se desarrolla a partir de intereses políticos y la esencia orientalista se mantiene, así como el racismo. Son constantes las alusiones a los ojos rasgados, piel amarilleada o el lambdacismo (5), extremadamente recurrente: "los hombres de ojos rasgados", "de sonrisa enigmática", disciplinados: "A los pueblos orientales, desde Marruecos hasta Indochina, les gusta ser mandados y que les impongan lo mandado."

China tiene "sutil inteligencia oriental", el arte es "exquisito", así como una "cultura y sentido del humor (¿') milenarios". En cuanto a la religión y filosofía hasta tal punto llega la confusión en la que la prensa europea no consigue diferenciarla filosofía clásica China con la religión, poniendo al mismo nivel taoísmo, confucionismo y budismo.

La inaccesibilidad es una de las características más atribuidas a China desde los primeros contactos: "Hay que tener el "toque chino" para entender que sucede en el país del "peligro amarillo" (ABC, 18 Enero 1969) o "la comida china para degustarla hay que ser chino" afirma José Antonio Sangroniz en un artículo (ABC, 31 Mayo 1970). ¿A qué se refiere el $A B C$ con el "toque chino"? Este aura críptica e indescifrable atribuida a China otorga a aquel que escribe o lee sobre ella el permiso tácito de la simplificación, aunque sea en este caso una simplificación que descansa en realidad en una "sobre-complejización": esto es lo se sabe sobre China. Comprendemos que hay más, pero no podemos acceder a ello por no tener el "toque chino" o no ser chino.

Desde luego son innegables algunas barreras existentes que dificultan la comprensión de un país como China (lengua, diferencias culturales, obstáculos políticos), pero interponer limitaciones teóricas abstractas ("chinidad" como llave del conocimiento) al entendimiento solo refuerza argumentos simplistas y cierra la puerta a la realidad china.

El lenguaje y los medios de expresión chinos, están también representados con un aire orientalista. Existe un desconocimiento de los caracteres y grafía china, además de no diferenciar la escritura japonesa y china. Este hecho en realidad es bastante comprensible y no se puede 
pretender que los editores del $A B C$ supieran lengua china, sin embargo la confusión no lleva únicamente a colocar desorientados los caracteres (caracteres girados $180^{\circ}$, o en espejo), sino directamente al atrevimiento de ingeniar caracteres nuevos a partir de la inventiva o de ideas preconcebidas, una idea orientalista del lenguaje y la cultura que llevaba generándose desde siglos anteriores (Tong, 2000, 6-20).

A finales de Febrero de 1972 aparece una noticia extraordinariamente popular con imágenes de un parto por cesárea en el que la paciente esta anestesiada exclusivamente con técnicas de acupuntura realizado ante periodistas estadounidense (ABC, 27 Febrero 1972, p.17). Estas mismas imágenes aparecen en la película "Chung Kuo" de Michelangelo Antonioni (1972). Es durante esta época en la que empieza a nacer la atracción por la medicina oriental: acupuntura, moxibustión, fitoterapia... Así, aparecen en el ABC y en la revista "Blanco y Negro" monográficos sobre el tema tratando de explicar de la manera más fiel posible el funcionamiento de estas técnicas (ABC, 9 Abril 1972, p.28). Es quizá uno de los pocos puntos en los que el imaginario occidental y la realidad china logran sincronizarse, aunque sean por embates distintos. En Occidente se busca la confirmación de una representación tradicional de China, mientras que en la RPC se busca un impulso de estas prácticas alejándose del misticismo inmanente y profundizando en su materialización científica (Baum, 1982).

Sin embargo el hecho más trascendente en cuanto a la percepción de China se da a partir de 1971 coincidiendo con la admisión de la RPC en la ONU. "La China Roja vuelve a sonreír" (Blanco y Negro, 17 Febrero 1973, p.55), afirma el titular de un monográfico. Aunque la relajación de la Revolución Cultural tiene mucho que ver, la entrada de China en la ONU obliga a dar un giro a la forma de representar el país. La perspectiva de un reconocimiento por parte del gobierno español a corto plazo (9 de Marzo de 1973), otorgaba a la prensa la labor de modificar paulatinamente la percepción de la RPC, al menos en su papel político a nivel internacional, y acogerse a la "Realpolitik" para justificar las decisiones del gobierno español.

\section{Amenazas}

Como mujeres ataviadas con sus armaduras brillantes, las naciones europeas contemplaban a lo lejos una inmensa estatua de Buda que resplandecía sobre el humo de una ciudad en llamas. El pie de la ilustración explica: "Pueblos de Europa, proteged vuestros bienes más sagrados". (6) El temor y la amenaza de los pueblos asiáticos sobre Europa no es un elemento nuevo en la historia de occidente. El llamado "Peligro Amarillo" o "Terror Amarillo", es un término comúnmente concedido al Kaiser Guillermo II de Alemania a finales del siglo XIX para referirse sobre todo al nuevo peligro creciente que, supuestamente, conformaba Japón. Sin embargo, con el tiempo se hizo extensible a Asia en general. Casi un siglo después, hasta los años sesenta y setenta del siglo XX, llega en forma de amenaza global en la figura de China.

La mera existencia de la República Popular China consistía una amenaza en sí misma. Una amenaza multilateral que no se limitaba únicamente al terreno militar (aunque es quizá la más clara) sino que se extendía a otros ámbitos. Para comprenderlo es necesario ahondar en el mensaje que el diario $A B C$ transmite a sus lectores. Para este trabajo se han diferenciado varios conjuntos de amenazas que están irremediablemente interrelacionados: Amenaza militar, política, ideológica, racial, religiosa y social. Durante el último periodo (finales de los años setenta) comienza a constituirse una amenaza económica muy ligera y de baja representación en 
SERGIO SÁNCHEZ FRAILE: Imagen de China y su representación en la prensa española en las décadas de 1960 y 1970: el caso del ABC

la prensa, pero se ha creído conveniente citarla por el desarrollo que tiene hasta la actualidad.

Militar: El contexto militar de la Guerra Fría está cubierto con un halo de paranoia posiblemente inaudito hasta entonces. Para Occidente la realidad era que el comunismo no constituía una amenaza física sin la bomba nuclear. Con ella, en cambio, se producía una dinámica de enfrentamiento irresoluble: la mezcla de ideologías irreconciliables con armamento tan poderoso sólo podía llevar a la destrucción de ambos contendientes (Pierce, 2000), por lo que la entrada de China en este juego nuclear genera suspicacias peculiares.

Comienza a percibirse, ya desde principios de 1960, cómo la prensa va desplazando el eje de la tensión política y militar desde Europa hacia Asia, dando a entender que sería China y no la URSS la verdadera amenaza para Occidente.

En el momento en el que la RPC comienza a desarrollar lo que se cree son armas atómicas el periódico toma una postura bipolar. Por un lado trata de demostrar la amenaza constante que supone China en el ya delicado contexto de la Guerra Fría. A la amenaza que constituía la URSS se le añadía ahora China, un país desconocido, que no se sabía cómo podía reaccionar, ya que era tan sibilino. Sus políticos además de comunistas (por naturaleza, agresivos e impulsivos) pertenecían a una cultura que no se regía por una diplomacia tradicional sino que se dejaban llevar por sus pasiones revolucionarias. Se despliega una sensación de imprevisibilidad que acentúa el miedo y la paranoia. La URSS, aunque era comunista, a nivel diplomático no dejaba de ser Rusia, país conocido por la política europea, que se había desviado en su devenir histórico. Rusia era además de tradición cristiana y de raza caucásica. Es el "Telón de Bambú" frente al "Telón de Acero". China, debido a su potencial demográfico no tiene miedo a la bomba atómica, ya que "por muchos que mueran, bastantes quedarán" o "China se convertiría en dueña del mundo en caso de guerra", hasta tal punto que aparecen ya durante los años sesenta líderes soviéticos mostrando su temor hacia la RPC.

Por otro, sin embargo, se menospreciaba de manera reiterada cualquier esfuerzo de modernización militar por parte de la RPC y se ridiculizaba, tachando de "cuento de hadas" las pruebas atómicas chinas y reafirmando que el potencial militar de EEUU y las potencias occidentales era largamente superior. Se trata de hacer un equilibrio del miedo dentro de una "paz nuclear"(Wohlstetter, 1958). Los lectores debían temer al comunismo, debían temer a la China Comunista y también a la URSS, pero no tanto como para que ello afectara en demasía a la población y se activara un pánico global que afectara de manera significativa a la economía y la producción; controlar a la población, sin destruir la moral.

China se convierte en el primer país no-blanco (importante para comprender China como amenaza racial) en obtener la bomba atómica. Ya no solamente el poder en sí de la bomba, sino que se lleva un registro del desplazamiento de la nube radioactiva. La omnipresencia de la radiación, la muerte en todas partes, no hay donde huir. Una suerte de peste negra en el siglo XX. Sin embargo se mantiene la política de equilibrio del miedo, donde primero se afirma que tiene la potencia de la bomba de Hiroshima luego se dice que son simples juguetes al lado del potencial militar de los EEUU y que en realidad Pekín teme a los EEUU (ABC, 24 Mayo 1966, p.52).

La postura del PCCh sobre la inevitabilidad de la guerra entre el campo socialista y el capitalista fomenta esta imagen de China ofensiva, llegando a una pequeña crisis de los misiles europea (ABC, 
22 Septiembre 1966, p.34), tras la sospecha de una base de misiles china en Albania. Hay otras referencias más o menos sensacionalistas para reforzar esta imagen de China como amenaza militar: pilotos suicidas, herencia directa de los "kamikaze" japoneses (remembranza del desastre norteamericano en la Segunda Guerra Mundial en el Pacífico), teorías sobre la presencia de submarinos chinos en el Índico, niños soldado entrenados desde muy pequeños o las imágenes de mujeres esgrimiendo un fusil (una sociedad estaba preparada para la guerra inmediata).

El momento en el que tiene lugar el enfrentamiento armado entre la URSS y la RPC (1969) en la frontera sino-soviética se entiende como el inicio de una catástrofe a nivel mundial y no ya como el enfrentamiento que podía beneficiar a Occidente en su lucha contra el comunismo soviético y chino. El historiador Arnorld Toynbee aseguraba que hasta tal punto llegaba el nivel de miedo a la RPC que sería el elemento cohesionador de la humanidad contra la posible agresión china (ABC, 9 Enero 1970, p.20). Dato curioso, si es que puede incluirse en amenaza militar, es que se llegan a elaborar las dantescas teorías sobre un salto conjunto de toda la población china al mismo tiempo para generar una cadena de terremotos que podrían llegar hasta California (ABC, 18 Febrero 1970).

En una encuesta realizada por el Departamento de Encuestas del Centro de Estudios Económicos y Matemáticos de París, publicada primero en la revista "Paris-Match" y reproducida en Junio de 1970 por el $A B C$ se llega a la conclusión de que China es la mayor amenaza para la paz en el mundo (ABC, 20 Junio 1970, p.36). Además de considerar la Tercera Guerra Mundial más o menos inminente (58\% de los encuestados), el $68 \%$ creen que en esta la RPC será uno de bandos enfrentados, siendo su oponente o bien Estados Unidos (38\%) o bien la URSS (30\%), y solo un $7 \%$ considera que esta tendrá lugar entre EEUU y la URSS, perfecto reflejo ya no solo de la sociedad francesa, sino probablemente extensible a parte de la población europea.

Política: Aparte de la amenaza que en sí misma supone la República Popular China como país comunista, caso en el podríamos hablar mejor de amenaza ideológica, se muestra a China como una mala influencia sobre los países no alineados (África y América Latina), y más aún tras entrar en la ONU. Sin embargo, su aislamiento político sería aun más peligroso, al no estar presente en los acuerdos de desarme.

Al morir Mao, un escenario imaginado en el que la URSS y China retoman sus relaciones podía poner las estrategias de política exterior del revés por lo que al final del día era preferible mantener a China cerca de las potencias occidentales.

Ideológica: China constituía también una amenaza ideológica, representada no sólo en el comunismo sino también en el maoísmo.

A partir de la ruptura sino-soviética, comienzan a aparecer grupos minoritarios que se posicionan al lado de China y que adoptan el maoísmo como ideología y a China como nuevo modelo del comunismo internacional al entender que la URSS había abandonado el marxismo-leninismo.

A pesar de no ser muy numerosos el diario comienza a hacerse eco de la aparición de estos grupos "pro chinos" en Europa a inicios de los años 60, siendo Albania el cuartel general del 
maoísmo en Europa (sobre todo durante el "Autunno caldo" italiano, pero también Bélgica, Francia y España) y lugar de referencia de estos grupos hasta la muerte de Mao y la ruptura del gobierno albanés con Hua Guofeng.

El propio periódico se da cuenta con sorpresa de la llegada de influencia china a Europa, aunque sea de forma estética. Habla en Enero de 1968 de la "Maomanía":

"Se trata de libros, de modas, de motivos decorativos inspirados en la China Popular, en la llamada «revolución cultural». Todo comenzó, se dice, con la aparición del famoso libro rojo con pensamientos de Mao Tse-tung, del que se vendieron en su primera edición francesa más de cien mil ejemplares en poco tiempo, convirtiéndose en un «best-seller». Después vinieron las películas - «La chinoise», de Jean-Luc Godard, y «La China está próxima», de Marco Bellocchio, entre otras- que tenían por motivo el país de Mao. Y más tarde, las prendas inspiradas en la vestimenta china, como las túnicas abrochadas hasta el cuello acompañadas de estrechos pantalones, y los mil motivos decorativos tomados del mundo pekinés." (ABC, 6-7 Enero 1968).

Para la prensa en España, estos grupos eran elementos subversivos dispuestos a romper el orden público en la defensa de una ideología extranjera, aún más ajena que el comunismo soviético, y contraria completamente a los principios del Movimiento.

Racial: La postura de un periódico como el $A B C$ (conservador, católico y monárquico) ante el crecimiento y el desarrollo de un país como China (comunista, ateo y además no-blanco) no es en absoluto una sorpresa. El baby boom que había tenido lugar en occidente tras la Segunda Guerra Mundial y que termina en los años sesenta, cede su relevo a China. Este aumento de población no aparece como un problema ecológico o demográfico sino como una amenaza primero para la hegemonía de la raza "occidental" y después como un peligro para la expansión del catolicismo en China.

Amenaza que se podría extender hacia la política, ya que el aumento de población supone que los ideales democráticos de "un hombre, un voto" sólo debilitan a occidente en este panorama de crecimiento demográfico (China, India, países africanos) (ABC, 15 Abril 1962, p.82)., entendiendo el mundo afroasiático aceptaría mejor el liderazgo de un alguien "amarillo" como Mao, que uno "blanco".

La lógica del $A B C$ es clara: la consecuencia de un posible desarrollo futuro de China es la desaparición de la cultura y los valores occidentales.

Así, acontecimientos como la Revolución Cultural, se revisan desde un punto de vista eurocéntrico, cristiano y blanco, representada como un movimiento que aparte de las implicaciones internas que tiene, es predominantemente xenófobo y persigue la religión cristiana.

Religiosa: En este caso se hace una distinción muy clara entre la China Continental y Taiwán, y en parte Hong Kong. Mientras que la RPC supone una amenaza para el catolicismo, Taiwán se constituye como receptora de misiones católicas, y defensora del catolicismo y la religión cristiana. Esto es fácil de entender ya que Sun Yat-sen (孫中山, Sūn Zhōngshān) uno de los fundadores del Kuomingtan y Presidente de la República de China antes de la victoria comunista, y 
ChiangKai-shek (蔣介石, Jiǎng Jièshí), Presidente de la República de China en Taiwán durante 25 años (1950-1975), eran ambos cristianos. En este sentido Taiwán comulgaba (manteniendo las distancias) con los preceptos del movimiento nacional-católico español. La RPC tenía el objetivo de crear una iglesia católica cismática nacional a partir de la "Asociación Patriótica Católica China" (中国天主教爱国会, Zhōngguó tiānzhǔjiào àiguó huì), que desvinculaba el catolicismo de la autoridad papal.

Las noticias que aparecen sobre los ataques a católicos en China se cuentan en tono martirizante y en muchas ocasiones épico, comparándolo con la persecución a los cristianos por los romanos.

La tarea del $A B C$ es representar a China como un país bárbaro en el sentido más clásico del término. No sólo no se deja civilizar, sino que persigue a los cristianos (Roma cristiana/bárbaros), o bien trata de alejarlos de su fe con trucos políticos e invenciones oportunistas como la Asociación Patriótica Católica China (sincretismos y religiones estatales).

Social: La China desconocida e intrigante que pone en peligro los valores y la hegemonía occidental (blanca y cristiana) amenaza igualmente a la sociedad española y europea, tratando de desgastar su entereza y su moral a través del comercio de droga. Durante los años sesenta la droga se convirtió en enemigo público número uno de la sociedad occidental. La prensa y los medios de comunicación desplegaban su arsenal de imágenes e historias sobre los problemas que la droga causaba en la juventud europea y norte americana, minando los valores del futuro del país y generando una paranoia social sobre la destrucción de la sociedad (Goode, 2008, p.533-543).

En este contexto los vendedores eran en esencia el origen de este mal que "asolaba" occidente. Un mal tangible, las drogas, que provenía de un mal abstracto, el comunismo. Combatir uno era combatir el otro. No obstante, la URSS combatía esa misma batalla al otro lado del telón de acero (Kramer, 1990, p.19-31). Se señala como la República Popular China nace como un país exportador de droga, con el que financia su revolución:

Jamás podrá destruirse en su mayoría la producción de drogas, mientras la China Roja siga existiendo, la Gran Fábrica sigue trabajando a ritmo acelerado. Si ella dejase de existir, las "pequeñas fábricas" esparcidas por otros países, podían ser debidamente controladas y aniquiladas.(ABC, 16 Noviembre 1966, p.35)

La lógica de la Guerra Fría explica que se acuse a China como uno de los principales productores de droga, creando así este vínculo de demonización droga-comunismo, que además estaría reforzado por la relación histórica de China con el opio, aunque no funcionara exactamente a la manera en la que aparece representada en la prensa española.

Finalmente, podríamos incluir aunque de manera muy breve y con muchos matices una amenaza económica. Esta solo se produce a partir de la segunda mitad de la década de 1970 cuando comienza a verse, con el reconocimiento de la RPC, una ligera apertura en el comercio entre España y China. Esta amenaza se hace manifiesta por primera vez en el ABC a finales de Abril de 1975 en una noticia sobre la exportación de mantones de Manila y el perjuicio que supone para los artesanos tradicionales españoles. Sin embargo, parece que este supone un 
SERGIO SÁNCHEZ FRAILE: Imagen de China y su representación en la prensa española en las décadas de 1960 y 1970: el caso del ABC

caso aislado, ya que rara vez vuelve a aparecer una noticia similar, mientras que si aparecen mucha publicidad de los nuevos artículos que están llegando desde China a España.

En general, a partir de la muerte de Mao (1976) una vez estabilizado el poder bajo la figura de Hua Guofeng y la rehabilitación de Deng Xiaoping, la imagen amenazante de China comienza a decaer, aunque no desaparece, en favor de una imagen de transición hacia la coexistencia pacífica.

Se puede hablar de varios factores que parecen contribuir a este cambio de perspectiva en la prensa:

- La visita de Nixon a China y el proceso de normalización de la Republica Popular.

- El reconocimiento formal de China por parte de España y su entrada en la ONU.

- La muerte de Mao y la persecución de la Banda de los Cuatro como fin marcado de la Revolución Cultural y sus consecuencias más graves.

- El aumento de intereses económicos mutuos y de los intercambios comerciales.

Paulatinamente van apareciendo noticias sobre el restablecimiento de algunas tradiciones o el levantamiento de prohibiciones, como algunos autores, música y arte occidental (ABC, 26 Mayo 1977, p.47), así como la rehabilitación de intelectuales y de películas provenientes de Europa y EEUU (ABC, 10 Febrero 1978, p.39). El propio $A B C$ es consciente de esta nueva imagen que China está proyectando (Blanco y Negro, 15 Febrero 1978, pp.33-35). La pregunta nuevamente sería si es sólo la Republica Popular quién está cambiando o es todo el contexto el que modifica la imagen que el $A B C$ y la sociedad española perciben de China.

\section{Contactos}

Es necesario también examinar cuál es la proyección que el diario hace en el momento en el que ambas culturas entran en contacto, lejos de todo protocolo institucional. El caso que se usa a continuación es un ejemplo claro de la imagen postcolonial que ofrece el $A B C$ sobre China sin tan siquiera sonrojarse.

Es la historia de Bong Way Wong, el chino torero (ABC, 22 Febrero 1969, pp.36-43). José Medina Gómez, presenta en este reportaje el caso de un estadounidense de ascendencia china (Guangzhou) que está aprendiendo a torear. Todos los recursos descriptivos usados durante el artículo se acercan al orientalismo (por no decir al racismo) por el mero sensacionalismo. El articulo lleva por titular: "El honorable torero Bong Way Wong" ya nos da antes de empezar un ramalazo de chiste "oriental" aludiendo al clásico apelativo de "honorable" para el emperador durante los rituales de las embajadas extranjeras en China, y reproduciendo así una escena más cercana a la ficción cinematográfica que a la realidad histórica. Y continúa con desafortunadas referencias raciales: "[...] tiene saltarines los ojos oblicuos y su piel parece convalecer de una ictericia."

Con todo, y aunque el propio autor del artículo afirma que ni es nacido en China ni conoce China, todo son comparaciones recurrentes: "el chino y el andaluz tienen una rara sensibilidad para el sufrimiento", o comparaciones sobre la coleta manchú y la coleta de los toreros.

Este caso se recupera tres años más tarde (ABC, 23 Junio 1966, p.80) en un artículo de Carlos Luís Álvarez (bajo el pseudónimo de "Cándido") para seguir en la misma línea descriptiva bastante esclarecedora: 
"Cuando llegue la hora de usar la mano "izquielda" el torero chino Bong-Way sentirá una emoción exótica de la que no hay precedentes en China. [...] Además ¿quién puede haberte aconsejado que salgas a torear vestido de chino? Si verdaderamente quieres llegar a ser "el niño de Cantón" (¡mi madre, que apodo!) ya puedes ir quitándote el quimono, porque de otro modo no tienes nada que hacer. [...] Chino valiente y raro. Pero ¿sabes bien dónde te vas a meter, chino? No, no lo sabes. [...] Si sales a la arena con quimono, chino bueno, no salgas con espada, sino con un alfiler de jade; que del toril no salga un toro, sino que baje de las nubes una mariposa; que no luzca el sol, sino que "se enciendan los faroles de seda en la terraza del Oeste", $y$, en fin, que la charanga no toque pasodobles, sino que suenen las cuerdas de un laúd al ser acariciadas por el viento. [...] ¿Cómo es, BongWay Wong, que te ha entrado el come-come de los toros? ¿Tal vez ocurrió todo aquel día, mientras peinabas solícitamente tu grácil coleta de chino fiel? ¿Qué harás, si decides hacerte torero, cuando tengas que cortarte la coleta? ¿Te la cortarás? ¿Seguro que te la cortarás? Mira, BongWay Wong, que esto es una cosa muy seria."

Por desgracia, el protagonista de la noticia tuvo una cogida en la corrida que mencionan en la noticia anterior en San Sebastián de los Reyes.

Este ejemplo resume probablemente gran parte de todo el trabajo que se ha realizado hasta ahora. La escasa comprensión sobre China lanza al diario $A B C$ a una suerte de atrevimiento literario, dando palos de ciego sobre una imagen de China ya maltrecha. Las constantes referencias a la China imperial, la raza, incluso hacer burla usando un manido recurso como es el "lambdacismo" clarifica las dudas acerca de cuál es la imagen que el ABC proyecta a sus lectores sobre China.

Dejando a Bong Way Wong de lado, a partir de 1973 con el reconocimiento de China comienzan a aparecer en el $A B C$ anuncios y publicidad sobre la entrada y venta de productos de la RPC en España. Es cuanto menos curioso la diferencia en la percepción de los productos chinos durante la década de 1970 (durante los sesenta no hay un volumen significativo) y la que se ha "cultivado" en la actualidad. Serán sobre todo las grandes cadenas comerciales españolas las que anuncian estos productos, como SEPU, Galerías Preciados y El Corte Inglés. Los símbolos clásicos de oriente están permanentemente representados y se habla aun de sedas, alfombras, porcelanas, muebles, en general productos de gran calidad. Ya no solo eso sino que hay cierta confusión en el simbolismo oriental y de lo que es chino y lo que no, como los kimonos. La proyección en estos anuncios es todavía más orientalista aun que las descripciones del $A B C$, quizá por dirigirse a una masa consumidora que compra bajo una idea preconcebida sobre qué es China.

De igual modo comienzan a aparecer anuncios de agencias de viajes que realizan paquetes de vacaciones a China, con la misma persistencia: "cultura y civilización milenaria", "costumbres ancestrales", "país insospechado, exótico, desconocido", o de nuevo el lambdacismo, en un anuncio (ABC, 14 Octubre 1979, p.13) de la compañía alemana "Lufthansa": "Disflute Vd. sus vacaciones en un lugal lejano -pol ejemplo, en China."

Sin embargo, se admite como hemos visto anteriormente el desconocimiento, por lo que su 
SERGIO SÁNCHEZ FRAILE: Imagen de China y su representación en la prensa española en las décadas de 1960 y 1970: el caso del ABC

reproducción se hace aún más atrevida y menos justificable. La comprensión general de China en España durante este periodo viene muy bien resumida en un párrafo de un artículo de Baltasar Porcel a mediados de Junio de 1973:

"Pero, aparte de las noticias servidas aquí por la Prensa, todas ellas políticas y más o menos sensacionalistas, ¿encontraríamos entre nosotros un conocimiento equivalente sobre China, a nivel popular y hasta universitario? ¿Y un respeto hacia sus formas políticas? Lo dudo. La actitud de los chinos, excusándose por no saber nada de España, por no poder confeccionarse una idea sobre nuestro país partiendo de lo poco que sabían, contrasta vivamente con la posición adoptada por docenas de personas con las que he conversado a mi vuelta: sin apenas saber nada de allí formulan, impávidos, contundentes juicios.

La «moda china» que se ha extendido por el país después del establecimiento de relaciones, ¿se limitará a cultivar un anecdotario socarrón o nos impondrá la necesaria dosis de prudencia para conocer antes de juzgar? Establecer relaciones humanas es tan importante como hacerlo con las diplomáticas. Y acaso más." (ABC, 17 Junio 1973, p.11)

El desconocimiento, sin embargo, no mengua la importancia que China estaba adquiriendo durante los años 70. El interés del público por conocer el país asiático se hacía patente a través de la gran cantidad de libros sobre China que se estaban publicando y el volumen de noticias sobre el tema que aparecían en la prensa. De ello se hacía eco Jorge Uscatescu en un editorial:

No es solamente el tema de moda. Es, podemos decirlo sin temor a exagerar, el gran tema. Lugar de peregrinación occidental, objeto de fascinación constante, enigma sometido a todo tipo de decifraciones, China es, sobre todo, en un sentido amplio, la atracción suprema. Atracción que tiene un nombre: el libro. El libro que abunda, los libros sobre China, los escritos sobre China, tema constante, abierto a todas las improvisaciones. [...]

Discurso que no invalida la pregunta de Etiemble en su «vademécum» lúcido y positivo sobre China. ¿Alguien conoce China? Pregunta que justifica la creciente aventura de los que van hacía esta gran desconocida fascinante incógnita del nuevo, absurdo y caótico «equilibrio» de fuerzas. (ABC, 29 Febrero 1976, p.44)

Finalmente, uno de los acontecimientos que aportarán más visibilidad a China dentro de la población española será la visita del Rey Don Juan Carlos I y la Reina Doña Sofía a la RPC. EI viaje tiene lugar del 16 al 21 de Junio de 1978, donde el rey se entrevista con Deng Xiaoping y Hua Guofeng. La prensa muestra la visita como un acontecimiento clave para la historia de las relaciones entre España y China, y destaca reiteradamente la increíble acogida que han tenido los Reyes de España en su vista. (ABC, 20 Junio 1978, p.3)

\section{CONCLUSIONES}

Tras el exhaustivo análisis a las fuentes primarias y el trabajo de investigación, parece necesario si no obligatorio extraer unas conclusiones al respecto. Aunque este estudio se ha realizado únicamente con fuentes primarias y documentos del diario a $A B C$, habría que examinar si es extensible a la mayoría de la prensa diaria publicada en España en los años sesenta y setenta. Aun así, nos ha servido para acercarnos bastante a la imagen y la representación que la prensa hace de China. 
Se ha corroborado un intento de comprensión de la realidad China, pero con limitaciones. Estas limitaciones aparte de ser geográficas, políticas, lingüísticas o culturales, son de desconocimiento absoluto sobre el país, y se reconocen y se admiten como propias a la hora de exponer la información. Esto no evita la reproducción de algunas ideas preconcebidas sobre China a sabiendas de estar posiblemente cayendo en el error.

En cambio, el desconocimiento no implica desinterés. La gran cantidad de libros publicados y traducidos, el incansable cauce de noticias, crónicas, monográficos sobre China lo constata: comienza a estar de moda durante este periodo, y lentamente este interés arrastrará sus pies lentamente hasta la actualidad.

Aun así, en cierto modo el diario presenta China como un ente muy complicado y lejano para ser asequible, por lo que lo más sencillo es simplificar los términos y los procesos complejos, haciéndolos a la vez asequibles pero carentes de sentido.

La proyección que se hace sobre China está basada en una imagen tradicional, postcolonial y orientalista, con las consecuentes resistencias a cambiarla. Esto supondría un ejercicio mental y un esfuerzo colectivo al que no se está dispuesto, y el imaginario social prefiere mantener una representación de China que no altere las preconcepciones clásicas. Cualquier alteración de este ideario tradicional, aleja al país de sí mismo y lo convierte en una China "sin alma china", que sí se conserva en la isla de Formosa. ¿Dónde está nuestra China? No se puede ser paternalista con un país comunista y que posee la bomba atómica, por lo que es mejor negar la realidad de la China revolucionaria de Mao, o bien aferrarse a los restos de un naufragio del siglo XIX.

Este desconocimiento coloca al país asiático en una posición amenazante, de peligro constante y latente, que aunque funciona sin problemas dentro de la dinámica de paranoia de la Guerra Fría tiene sus matices propios. A la amenaza clásica militar reforzada con el desarrollo de armamento atómico, se le une un miedo al control de las instituciones políticas internacionales, a la pérdida de la hegemonía racial caucásica a través del aumento desmesurado de población, y, unido a este, la perdida de la hegemonía cultural occidental a través de la persecución y destrucción de la civilización cristiana, que se completa con la desmoralización y el desgaste de los valores de los jóvenes occidentales a través de las drogas. Aun así esta amenaza irá disminuyendo paulatinamente, aunque no desapareciendo, según avanza el proceso de reconocimiento internacional.

\section{REFERENCIAS BIBLIOGRÁFICAS.}

- Baum, R. (1982). Science and Culture in Contemporary China: The Roots of Retarded Modernization. AsianSurvey, 22(12).

- $\quad$ Buchanan, T. (2012). East Wind: China and the British Left, 1925-1976. Oxford: Oxford University Press.. Oxford: Oxford University Press.

- Cardina, M. (2010). Margem de certa maneira: o maoísmo em Portugal : 1964-1974. Universidade de Coimbra. 
- Chuliá Rodrigo, E. (1999). La Ley de Prensa de 1966: La explicación de un cambio institucional arriesgado y de sus efectos virtuosos. Historia y política: Ideas, procesos y movimientos sociales. Centro de Estudios Políticos y Constitucionales.

- Davara Torrego, F. J. (2005). Los periódicos españoles en el tardo franquismo: consecuencias de la nueva ley de prensa. Comunicación y hombre: revista interdisciplinar de ciencias de la comunicación y humanidades. Universidad Francisco de Vitoria.

- Dirlik, A. (1996). Chinese History and the Question of Orientalism. History and Theory, 35(4), 96-118.

- Dirlik, A. (2015). Born in Translation: "China" in the Making of "Zhongguo." boundary 2.Consultado: 4 de Febrero, 2016, en <http://boundary2.org/2015/07/29/born-in-translation-china-in-the-making-of-zhongguo/>

- Duara, P. (2011). The Cold War as a historical period: an interpretive essay. Journal of Global History, 6(3), 457-480

- Dittmer, L. (2011). Two suns in the heavens: the Sino-Soviet struggle for supremacy, 19621967. Cold War History, 11(2), 278-279.

- Lia Mingjiang. (2011). Ideological dilemma: Mao's China and the Sino-Soviet split, 1962-63. Cold War History, 11(3), 387-419.

- Elbaum, M. (1998).Maoism in the United States. In Encyclopedia of American Left.

- Fields, B. (1984). French Maoism. Social Text, 148-177..

- Fontcuberta Balaguer, M. (1993) La noticia. Pistas para percibir el mundo. Paidos Iberica.

- Gómez-Reino y Carnota, E. (2007). La Ley 14/1966, de 18 de marzo, de prensa e imprenta: un modelo de autocensura. Dereito: Revista xuridica da Universidade de Santiago de Compostela.

- Goode, E. (2008). Moral panics and disproportionality: the case of LSD use in the sixties. Deviant Behavior, 29(6), 533-543.

- Kessel, P. (1972 y 1978).Le Mouvement maoïste en France, 1963-1968 (tome I et II). Paris: Union générale d'éditions.

- Kramer, J. M. (1990). Drug Abuse in Eastern Europe: An Emerging Issue of Public Policy. Slavic Review, 49(1), 19-31.

- MacFarquhar, R., \& Schoenhals, M. (2009). La Revolución Cultural china. Barcelona: Crítica.

- Merril, John C. (1968). The Elite Press: Great Newspapers of the World. Pitman Pub. Corp.

- Moradiellos, E. (2000) La España de Franco (1939-1975): política y sociedad. Madrid Síntesis

- Olmos, V. (2002). La Historia del ABC: 100 años clave en la Historia de España. Barcelona: Plaza \& Janes. pág 443-456

- Pierce, D. (2009). America in the Post War Period. Student Pulse, 1(10).

- Río, E. del. (2005). Influencia de la Revolución Cultural china en la izquierda europea y latinoamericana. In Izquierda e ideología (pp. 127-150). Madrid: Talasa

- Spence, J. (2011). En busca de la China moderna. Barcelona: Tusquets. (731-790)

- Tong, Q. S. (2000). Inventing China: The Use of Orientalist Views on the Chinese Language. Interventions, 2(1), 6-20.

- Toynbee, Arnold. (1977) El estudio de la Historia. Barcelona. Alianza Editorial

- Wohlstetter, A. (1958). The Delicate Balance of Terror. Santa Monica: The RAND Corporation 


\section{Otras fuentes}

- Hemeroteca ABC <http://hemeroteca.abc.es/>

- España. Ley 14/1966, de 18 de marzo, de Prensa e Imprenta. BOE, 19 de marzo de 1966, núm. 67, 3310-3315 Web: <https://www.boe.es/boe/dias/1966/03/19/pdfs/A03310-03315. pdf> [Consulta: 21 de Enero 2016]

\section{NOTAS}

(1) Hasta tal punto llega el monarquismo del ABC que en 1969 durante la votación para la sucesión de Franco en la figura del príncipe Juan Carlos de Borbón, Torcuato Luca de Tena vota "no" entendiendo que se debe respetar el orden sucesorio que recaería en Don Juan de Borbón.

(2) El profesor John C. Merrill incluye en 1968 en su obra "The Elite Press, Great Newspapers of the World" el diario ABC entre uno de los diez más influyentes del mundo junto con The Guardian, New York Times, Le Monde, Times, Pravda, Renmin Ribao y L'Osservatore Romano entre otros.

(3) Entiéndase "referencia" como la unidad en la que se presenta la palabra "China" en el diario $A B C$. Es decir, una sola noticia podría tener varias referencias.

(4) Los datos absolutos anuales nos dan los siguientes resultados: Década de 1960, 15.284, Década de 1970, 14.213, y Década de 1980, 15.212.

(5) Aunque se suele aplicar el término en la dialectología de la lengua castellana (Puerto Rico), sirve y es aceptado también en el caso de hablantes de castellano de origen asiático (Japón, Corea y China). También denominado "lalación", el fenómeno hace referencia a la dificultad fonética a la hora de pronunciar el sonido consonántico / $\mathrm{r} /$ siendo sustituido por /l/.

(6) "Völker Europas, wahrt eure heiligsten Güter" (1895) es una conocida obra del pintor alemán Hermann Knackfuss 